\title{
Witnessing intimate partner violence: Review of the literature on coping in young persons
}

\section{Kate van Heugten and Elizabeth Wilson}

Dr Kate van Heugten is the Head of the School of Social Work and Human Services, College of Arts, University of Canterbury.

Elizabeth Wilson is a PhD student at the School of Social Work and Human Services, University of Canterbury. In her research study, with the working title 'Engaging youth on their own terms: An ethnographic study of hip hop culture in youth work practice in Christchurch city', she is exploring the ways in which hip hop culture can be used by practitioners to engage with youth. Elizabeth's practice experience includes youth justice and mental health.

\section{Abstract}

Since the mid 1980s, there has been increasing concern about the impact that witnessing intimate partner violence (also commonly known as domestic violence or spouse abuse) has on children and young persons. In an article published in Social Work Review in 1994, Pamela Millen reviewed the international literature on children who witness such abuse and reported on strategies for intervening to ameliorate the negative consequences. This article updates her literature review, attending in particular to strengths-based and ecological perspectives that have emerged over the ensuing 15 years.

Social work research and literature on dealing with trauma has come to increasingly emphasise resilience (the capacity to bounce back from adversity), protective factors (buffers against the effects of trauma) and coping (managing difficulties). This focus on resilience is also encouraging a closer look at the perspectives of survivors, including survivors of childhood abuse. In-depth qualitative research has been undertaken with children and young people in order to gain a better understanding of their perspectives and coping strategies for dealing with the challenges of living with intimate partner violence, including their use of resources in the environment. Meanwhile, quantitative research has looked at relationships between a wider array of variables, raising questions about previous simple 'cause and effect' conclusions about the impact of intimate partner violence on children and young people. Research and literature that specifically address issues for young persons as differentiated from children remains scant.

\section{Introduction}

Until recently, the literature that considered the impact of witnessing intimate partner violence did not clearly distinguish the differential developmental capacities and needs of young persons in contrast to preadolescent children. Indeed, by being subsumed under the general heading of 'childhood' the particular strengths and opportunities of adolescence tended to be overlooked. 
This review was therefore undertaken in an effort to collect and present, in accessible form, information about how adolescents and young persons deal with their experiences of witnessing intimate partner violence toward a caregiver, and how service providers might respond to young persons in resilience-enhancing ways. Whilst we refer to 'young persons' in this article, for the purposes of the review we included literature referring to adolescents aged 10-19, and youth aged 15-24 (as defined by the World Health Organisation, 1989). Applying such a broad age band is clearly problematic, but reflects the lack of standardisation in the international literature on this topic. The following major themes emerged and are presented here: Services are frequently tailored to children, they lack capacity to assist young persons, and may overtly or inadvertently exclude them; young persons have been insufficiently involved in identifying their resource requirements; and the cognitive, social and physical development that occurs in adolescence and early adulthood allows for the utilisation of a greater range of coping strategies (Cunningham \& Baker, 2004; Goldblatt, 2003). Risk and adversity-based approaches may also fail to recognise the potential of young people, leaving untapped their capacity to be active witnesses and to support peers. In reviewing the literature, we found that most authors, despite an avowed commitment to a 'strengths approach', tend to revert to a 'problem focused' account on the subject. We attempt to redress this here by emphasising how even apparent 'problem behaviours' may be evidence of a desire to manage difficult situations, and by recommending investment in whole of community resilience-enhancing interventions.

\section{Impacts and coping strategies}

Local and international research estimates that approximately one quarter of young persons have witnessed intimate partner violence taking place in their home (Crime Research Centre and Donovan Research, 2001; Fergusson, Boden, \& Horwood, 2006; Fergusson \& Horwood, 1998; Fleming, et al., 2007; Martin, Langley, \& Millichamp, 2006). As also noted by Millen (1994) 'witnessing' refers to the different experiences that can come from living with intimate partner violence, such as seeing or hearing the violence or its consequences, as well as getting involved in the violent situation or its aftermath (Jaffe, Wilson, \& Wolfe, 1990).

Research since the mid 1990s has continued to accumulate data on the negative effects of intimate partner violence on children. Many impacts commonly cited are also relevant to young persons. Links have been found between exposure to intimate partner violence and increased mental health problems such as depression, anxiety and post-traumatic stress disorder (Fergusson \& Horwood, 1998; Fleming, et al., 2007; Humphreys, 2001; Margolin \& Vickerman, 2007; Martin, Langley, \& Millichamp, 2006; O'Keefe, 1996). Also more prevalent are addictions and suicide attempts, and behaviour problems including truancy. Links have been found between youth offending and aggression and exposure to intimate partner violence as children or adolescents (Fergusson \& Horwood, 1998; Fleming, et al., 2007; Herrera \& McCloskey, 2001). Young persons also relate feelings of over-responsibility for siblings and for the victimised caregiver, and a premature arrival at 'adulthood' (Cunningham \& Baker, 2007). Some studies suggest an association with witnessing intimate partner violence and diminished capacity to develop social skills and academic competence (Fleming, et al., 2007; Goldblatt, 2003). Indirect consequences of violence in the home, including frequent changes in location and lack of financial and other material resources, may disrupt peer relationships and stymie educational opportunities. 
It is possible that exposure to intimate partner violence puts young people more at risk of victimisation from other forms of violence. Fleming, et al. (2007), in a report on the results of the New Zealand-based Youth 2000 survey, found that adolescents who witness violence are significantly more likely to be victims of physical and sexual violence within and outside the home, and experience more bullying at school. However, the fact that these forms of victimisation befall the same young person does not prove that there is a direct causal relationship between them.

Recent research has begun to recognise that witnessing frequently takes place in a broader context of violence, and that observed negative effects might not be attributable solely to the experience of being present during the abuse of a caregiver, but might be due to multiple coexisting factors. Such factors include violence directed at the child itself, poverty, instability in housing and schooling (Fergusson, Boden, \& Horwood, 2006; Herrenkohl, Sousa, Tajima, Herrenkohl, \& Moylan, 2008; Margolin \& Gordis, 2000). As a result, questions are being raised regarding pessimistic deterministic predictions of future outcomes for youth who have witnessed intimate partner violence. For example, new research findings, including those from a longitudinal New Zealand-based child development study, counter previous negative assumptions about the 'intergenerational transmission of violence', showing that there is a lack of any strong statistical relationship between witnessing and perpetuating a cycle of intimate partner violence (Ernst, et al., 2007; Fergusson, Boden, \& Horwood, 2006).

The importance of these findings must not be underrated, as failing to consider the situation of children and young persons from a broader ecological perspective may potentially lead to detrimental reactive responses such as the removal of children from the care of non-violent caregivers (Edleson, 2004; Landon, 2000). Conversely, being alert to the impact of broader contextual factors draws attention to the need to resource efforts to overcome environmental stressors such as poverty and provide access to health care or educational opportunities for caregivers and their families.

In keeping with strengths-based perspectives, and in contrast with previous impact research which tended to cast children and young people as passive victims of negative consequences, researchers have begun to consider how young people actively utilise coping strategies (Barwick, 2004; Gilligan, 2006; Rhinas, 2006). Thus impacts are seen as the outcomes of young people's endeavours to manage ongoing life stressors. As already noted by Millen in her earlier review (1994), coping strategies are commonly categorised as externalising or internalising behaviours that may have positive and negative effects (Henderson, 1996). Examples of externalising behaviours employed by adolescents and young persons include the before mentioned substance abuse; self injury; sexual risk taking/promiscuity; early engagement in relationships including parenting to escape the family of origin; taking on emotional caretaker roles with siblings and parents; running away from home; and suicide attempts (Aymer, 2008; Cunningham \& Baker, 2004; Brady \& Donenberg, 2006; Fleming, et al., 2007; Humphreys, 2001; Joest, 2005; Kennedy, 2007). Negative consequences of such strategies may be evident in the short or longer term and include the pervasive effects on functioning of drug taking, risks of further victimisation associated with running away, and failure to complete educational qualifications. Reframed as coping mechanisms, however, we can begin to note that there are positive intentions and outcomes of these behaviours that include the immediate avoidance of painful feelings, and the achievement of a sense of control over, or opportunity to escape from, difficult 
situations. Internalising coping strategies may be more hidden, and include denial and emotional avoidance type behaviours, such as 'mental blocking' and 'emotional numbing' (Joest, 2005, pp.105-6). Such strategies have sometimes been linked with depression. When internalising coping strategies are generalised and applied outside of the context of intimate partner violence, they may become maladaptive, similar to externalising strategies, as they may cut the young person off from opportunities and resources, including the opportunity to develop relationship skills (Aymer, 2008; Brady \& Donenberg, 2006; Cunningham \& Baker, 2007; Cunningham \& Baker, 2004). However, whilst there are such drawbacks, emotional avoidance also serves to shield young persons from experiences until they can process these more safely.

Whether the route to escape is active and externalising or appears more passive and internalising, we note that all of these coping mechanisms involve a physical or cognitive / emotional absenting. There is no good evidence that temporary avoidance or evasive action is necessarily detrimental. For most young persons, this probably constitutes a necessary and temporary reprieve that assists them to survive until their circumstances improve and they are better resourced to develop violence-free functioning. If, however, their coping mechanisms are simplistically and negatively labelled, for example as evidence of criminality or mental illness, this may increase the likelihood that they will lead to unhappy trajectories, such as entanglement in the criminal justice system, from which the young persons may find it difficult to escape.

Reframing the above externalising and internalising behaviours as coping mechanisms requires a shifting of our focus to note their protective intent. Other coping strategies are more obviously adaptive and evince, as well as provide pathways for strengthening, resilience. One common adaptive strategy cited by young persons participating in research is to take time out from negative experiences through engagement in activities outside of the home, pursuing interests in sport, nature, an after school job, school work, or other extra-curricular activities. Some of these activities also function as avenues to deal with negative feelings and to gain self-confidence through experiencing success at a given task. Some participants mentioned the benefit of being able to interact with peers and form friendships without the pressure of having to involve their home environment (Goldblatt, 2003; Humphreys, 2001; Rhinas, 2006). In addition, Rhinas (2006) suggests that these activities also provide exposure to positive role models.

More research is needed to explore diverse pathways to resilience and gain a better understanding of how coping strategies are used and perceived across cultures. However, despite further work being needed to discern cross-cultural differences, we do know that the majority of strategies involve the use of informal rather than formal supports, whether it be a supportive family member, neighbour, a sports coach, teacher, or group of friends (Anderson \& Danis, 2006; Hardesty, Campbell, McFarlane, \& Lewandowski, 2008; Humphreys, 2001; Mullender, et al., 2002; Seith \& Bockman, 2008).

Another common adaptive strategy used by adolescents is to actively intervene in the violent situation. Anderson and Danis (2006) found this could mean:

... trying to stop the batterers, mediating between the batterers and their mothers, or running interference so the batterers could not get to their mothers or access weapons (p. 427-428). 
Safety planning is something learnt from a young age, and can involve proactive interventions such as talking with neighbours, calling the police and learning to drive to facilitate escape (Anderson \& Danis, 2006; Mullender, et al., 2002).

There appear to be gender and age-related differences in coping strategies, including a greater propensity for females to seek counselling support, especially as they mature. Humphreys (2001) found that once in early adulthood, young females sought counselling to heal from their experiences. Aymer's (2008) qualitative study of adolescent males found participants benefited from after school recreational activities such as sports, although men may also use reading. Just one of the eight male participants in Aymer's study sought out a school counsellor to deal with his depression. We did not locate research that identified whether and how the coping strategies of young people who have witnessed violence from an early age differ from the strategies applied by those who do not experience this until they are older.

Research suggests that where young persons exposed to intimate partner violence are able to utilise adaptive coping strategies, they can achieve positive outcomes, and their eventual resilience may outstrip that of people who have led more sheltered lives (Jaffe, Wilson \& Wolfe,1990; Kitzmann, Gaylord, Holt, \& Kenny, 2003; van Heugten \& Wilson, 2008). Such young persons note that they develop strong commitments to non-violent relationships with partners and children, although they may express uncertainty about their capacity to maintain such relationships under stress (Goldblatt, 2003). They take moral positions in contradiction to those emulated by violent caregivers. Indeed, these outcomes are not rare: most witnesses to violence grow up to be resilient and non-violent (Laing, 2000).

Highlighting young persons' potential to achieve resilient outcomes does not, and should not, equate to overlooking that even the most resilient of survivors have suffered and may continue to struggle (Goldblatt, 2003; Humphreys, 2001). Another important finding, made by researchers exploring young people's experiences of intimate partner violence, which practitioners need to keep in mind, is that young people commonly use a mixture of what are categorised as adaptive or maladaptive coping strategies (Aymer, 2008; Humphreys, 2001). These findings from the literature support working from a strengths perspective, improving accessibility of a range of supports, and helping young people build on their adaptive coping strategies (van Heugten \& Wilson, 2008). However, a recent focus on the importance of early intervention could lead to the belief that it is too late to attempt to foster adaptive coping and influence resilience during adolescence. In contrast to this assumption stands a view that resilience is not purely intrinsic but flourishes or degrades in a social context, and that furthermore, adolescence is a time of expanding developmental opportunity.

\section{Developmental opportunities}

The developmental watershed of youth is frequently approached from a rather negative perspective, but more researchers are recognising this period as a time of opportunity (Indermaur, Atkinson, \& Blagg, 1998; Wolfe, et al., 1996). There is much cause for optimism: young persons are ready to explore a world of ideas, beliefs and opportunities outside the family sphere. By adolescence they have access to internal cognitive resources such as the ability to decentre, imagine the world from others' perspectives, compare views and conceptualise alternative actions and outcomes. Adolescents are concerned with values and 
ideals, frequently including spiritual ideals. To inspire and support their exploration, they draw on information that differs from that provided by their immediate family, via school communities, employment, media such as the internet, and in particular via their peers. Their increasing interest in forming intimate relationships means they are often keen to gain knowledge on how to establish these. Above all, adolescents actively participate in, and set directions for, their own development (Goldblatt, 2003; Mulroney, 2003).

Research has also uncovered characteristics that help young people develop resilience; examples include self-acceptance, self-confidence, goal-setting, gaining a higher education, acceptance of family flaws, and the ability to learn from their own or others' mistakes (Humphreys, 2001; Rhinas, 2006; Suzuki, 2005; van Heugten \& Wilson, 2008). Being alert to the opportunities of youth can next lead us to ask if and how human service workers may play a part in helping them make the most of these.

\section{Approaches to intervention: Targeted approaches}

Millen (1994) highlighted overseas developments in programmes available for children who have witnessed intimate partner violence. Our review considered programmes for young persons, and found interventions developed overseas vary in focus, from those aimed at all young persons who have witnessed violence, to others which are targeted only to those who are considered 'at risk', or to those who have a particular need, such as mental health problems.

Our review revealed that researchers are now asking questions about which witnesses need formal interventions such as the group programmes or individual counselling outlined by Millen (1994). It is unlikely that the majority of young persons require or desire treatment-based services. The notion that such a need predominates may be inspired by culture-bound judgements that favour individualistic over communitarian approaches to enhancing wellbeing. It may also be based on culture-bound interpretations of what constitutes resilience: Joest (2005) asks, 'Who gets to decide what is or isn't resilient?' (p. 59), and gives the example of negative judgements that are directed at teenage pregnancy.

However, some young people, perhaps in particular those who face multiple adversities, do require specialist services. Internationally, few treatment programmes have been evaluated. Most evaluated programmes are delivered in a group work format and are directed toward children rather than being youth specific (Mullender, 2004; Shepherd \& Maxwell, 1999; Vickerman, \& Margolin, 2007).

In 1994, Millen highlighted many gaps in provision for child witnesses of intimate partner violence in New Zealand. Our review found that progress has been made in New Zealand under the Domestic Violence Regulations 1996, in terms of the development of more programmes targeted at witnesses of intimate partner violence (Wood, 2006). However, these programmes are not designed specifically for youth but rather for children in pre- or early adolescence (Cargo, Cram, Dixon, Widdowson, Adair, \& Jackson, 2002; Dunedin Women's Refuge \& Te Whare Pounamu Women's Refuge, 1999). An evaluation also found problems in the accessibility of these services. One major contributing factor to this predicament is that, in order to be eligible for these programmes, a Protection Order must be in place (Cargo et al., 2002; Wood, 2006). This requirement places an obstacle in itself, which is compounded 
by the fact that the law requires a person under the age of 17 to have a representative make an application for a Protection Order on his or her behalf. This is then clearly a situation where children and young persons lack an independent voice in getting their needs met. Whilst the Accident Compensation Corporation has provisions for funding of counselling or psychotherapy, this is not provided for victims such as witnesses who have not suffered direct physical impact abuse (Wood, 2006). Additional problems in accessing services and safe houses arise for families with mothers who have drug and alcohol problems (Wood, 2006). The situation in relation to availability of support may be worse for boys over 14 who are also denied help due to being excluded from staying in the majority of women's refuges (Wood, 2006).

An intervention currently being implemented that is enabling youth voices to be heard and their needs to be met is the Advocates for Children and Young People Who Witness Family Violence, a programme stemming from the Ministry of Social Development's Te Rito: New Zealand Family Violence Prevention Strategy (2002). Child advocates are also being included in Police Family Violence Safety Team pilots, with the goal of helping women and children receive needed services and support (Wood, 2006). Although these approaches appear promising, it remains to be seen if these services will give young people across the country the voice and support they need.

The picture is further complicated by the fact that services may be treating the outcomes of witnessing violence without this cause being clearly identified, for instance in mental health, or youth justice. We suggest that because of their ecological and strengths-based perspectives, social workers are particularly well placed to help raise awareness of the need to distinguish underlying from presenting problems, and to provide tailored support services. Strengthening our capacity to respond to the complex needs of young persons requires further development of co-ordination between agencies in New Zealand, which has been described as 'patchy' (Wood, 2006).

\section{Approaches to prevention and intervention: Universal approaches}

Targeted approaches contrast with approaches at the community prevention level, which involve educating not only those directly involved in intimate partner violence, but also community members, so they can become proactive as opposed to remaining inactive bystanders

Our review of the international literature reveals a strong case for the importance of universal or communitarian approaches. Adolescence is recognised as the appropriate time for prevention initiatives to help teens develop non-violent intimate relationships (Indermaur, Atkinson, \& Blagg, 1998). Many of these initiatives continue the established recognition that school-based programmes can offer much in the way of educating those who have witnessed or experienced intimate partner violence, their peers, as well as the wider community (Millen, 1994). The important role that peers can play in providing positive assistance and social support is also being recognised (Black, Tolman, Callahan, Saunders, \& Weisz, 2008; Jackson, 1998). Many prevention programmes have been developed overseas, and positive results have been reported for those that have been evaluated (Indermaur, Atkinson, \& Blagg, 1998; Mulroney, 2003). These results support the need for and expansion of schoolbased programmes in New Zealand, such as the dating violence prevention programme in 
Auckland which has been set up as part of Te Rito by the Ministry of Health (New Zealand Family Violence Clearinghouse, 2007).

However, young persons most at risk may not be in school (Kennedy, 2007). This population may be reached with new web-based resources that have been developed to help young people find information and support for themselves, or for friends who have witnessed intimate partner violence. Websites developed overseas can be used by youth in New Zealand. A good example of such an initiative is 'Bursting the Bubble' (www.burstingthebubble. $\mathrm{com} /$ ). This website notes the frequency with which young people experience both domestic violence and other forms of child abuse (McKenzie, 2003). The website offers quizzes, true stories with which young persons can identify, practical suggestions about steps to take, and links to websites and support services. It also contains advice for those wanting to help a friend (Domestic Violence Resource Centre, n.d.). Such initiatives also address the finding that children and young people are under pressure to avoid being seen to seek help from people outside of the family (Barker, 2007; Mullender, et al., 2002; Seith \& Bockman, 2008). This preference for anonymity has been recognised in New Zealand by YouthLine, who offer advice and support via websites, text or email (Youth Helpline, 2008).

Whole of community approaches are potentially less oppressive of minority groups. Public education campaigns make information accessible to all, without provoking the degree of stigma and shame that occurs when 'target populations' are identified (CrichtonHill, 2001)

However, neither targeted nor whole of community prevention and intervention programmes can address the effects of violence in isolation from the socio-economic and cultural contexts in which these are found to most negatively impact. If research findings that point to ecological contexts as being central in turning the immediate distress of witnessing violence into longer-term consequences are valid, failing to address underlying problems of poverty, discrimination, unequal access to resources of education, health or social support is ultimately neglectful (Boshier, 2006; Carter (n.d); Fordham, 2001; Hassall \& Fanslow, 2006; Indermaur, Atkinson \& Blagg, 1998; Kingi, 1999; van Heugten \& Wilson, 2008).

\section{Conclusion}

This article has considered shifts in the literature that have emerged in the 15 years since Millen published her overview in 1994. In particular, we noted shifts in the specificity with which impacts, causes and developmental considerations are being addressed. The ecological context in which witnessing occurs may be as, or more impact-full than the witnessing of events per se. If young people have access to community-based resources beyond their immediate family home, they may be enabled to find necessary respite and build strategies to pursue positive non-violent life trajectories. Many of the problematic behaviours we encounter in young people who have witnessed violence can be reframed as attempts at coping in the face of trauma, thereby recognising their courageous endeavours to achieve a better life.

More broadly, young people who are resourced with skills to deal with the violence and trauma that is present in their environment may grow in confidence and self esteem, and be better equipped to be supportive peers, and later, aware partners and members of our 
community. Such a totality of community approach at once avoids labelling and stigmatising and draws attention to the need to overcome passivity or acceptance of abuse in all of us.

Acknowledgement. This research was made possible with the help of an Internal Research Grant from the College of Arts, University of Canterbury.

\section{References}

Anderson, K., \& Danis, F. (2006). Adult daughters of battered women: Resistance and resilience in the face of danger. Affilia, 21, 419-432.

Aymer, S. (2008). Adolescent males' coping responses to domestic violence: A qualitative study. Children and Youth Services Review, 30, 654-664.

Barker, G. (2007). Adolescents, social support and help-seeking behaviour: An international literature review and programme consultation with recommendations for action. Brazil: World Health Organisation.

Barwick, H. (2004). Young males: Strengths-based and male-focused approaches. A review of the research and best evidence. Wellington, New Zealand: Ministry of Youth Development.

Black, B., Tolman, R., Callahan, M., Saunders, D., \& Weisz, A.(2008). When will adolescents tell someone about dating violence victimization? Violence Against Women, 14(7), 741-758.

Boshier, P. (2006, 11 April). Domestic violence in New Zealand - Better outcomes for our families. Paper presented at the Tairawhiti Abuse Intervention Network Hui, Lawson Field Theatre, Gisborne. Retrieved, October 28, 2008, from http: / / www.justice.govt.nz / family/ publications / speeches-papers / ?inline=domestic-violence-betteroutcomes-april-2006.asp

Brady, S., \& Donenberg, G. (2006). Mechanisms linking violence exposure to health risk behaviour in adolescence: Motivation to cope and sensation seeking. Journal of the American Academy of Child and Adolescent Psychiatry, 45(6).

Cargo, T., Cram, F., Dixon, R., Widdowson, D., Adair, V., \& Jackson, S. (2002). Evaluation of programmes for children under the Domestic Violence Act 1995. Wellington, New Zealand: Ministry of Justice.

Carter, J. (n.d). Domestic violence, child abuse, and youth violence: Strategies for prevention and early intervention. San Francisco: Family Violence Prevention Fund, Retrieved, October 28, 2008, from http: / / www.mincava.umn. edu/link/ documents/fvpf2/fvpf2.shtml

Crichton-Hill, Y. (2001). Challenging ethnocentric explanations of domestic violence: Let us decide, then value our decisions - a Samoan response. Trauma, Violence, \& Abuse: A Review Journal, 2(3), 203-214.

Crime Research Centre \& Donovan Research. (2001). Young people and domestic violence: National research on young people's attitudes to and experiences of domestic violence. Canberra, Australian Capital Territory: Commonwealth Attorney-General's Department.

Cunningham, A., \& Baker, L. (2004). What about me! Seeking to understand a child's view of violence in the family. London, Ontario, Canada: Centre for Children \& Families in the Justice System.

Cunningham, A., \& Baker, L. (2007). Little eyes, little ears: How violence against a mother shapes children as they grow. London, Ontario, Canada: Centre for Children \& Families in the Justice System.

Domestic Violence Resource Centre Victoria. (n.d.). Bursting the bubble. Retrieved February 5, 2009, from www. burstingthebubble.com/

Dunedin Women's Refuge \& Te Whare Pounamu Women's Refuge. (1999, July). Group work for children experiencing family violence. Paper presented at the Children and Family Violence Effective Interventions Now Conference, Wellington, New Zealand. Retrieved February 9, 2009, from http: / / www.justice.govt.nz/pubs / reports / 1999 / family_conference/author_12.html

Edleson, J. (2004). Should childhood exposure to adult domestic violence be defined as child maltreatment under the law? In P. Jaffe, L. Baker, \& A. Cunningham (Eds.). Protecting children from domestic violence: Strategies for community intervention (pp. 8-29). New York: Guilford Press.

Ernst, A., Weiss, S., Del Castillo, C., Marvez-Valls, E., D'Angelo, J., Combs, S., et al. (2007). Witnessing intimate partner violence as a child does not increase the likelihood of becoming an adult intimate partner violence victim. Academic Emergency Medicine, 14, 411-418.

Fergusson, D. M., Boden, J. M., \& Horwood, J. (2006). Examining the intergenerational transmission of violence in a New Zealand birth cohort. Child Abuse E Neglect, 30(2), 89-108.

Fergusson, D. M., \& Horwood, J. (1998). Exposure to parental violence in childhood and psychosocial adjustment in young adulthood. Child Abuse E Neglect, 22, 339-357.

Fleming, T. M., Watson, P., Robinson, E., Ameratunga, S., Dixon, R., Clark, T., et al. (2007). Violence and New Zealand young people: Findings of Youth2000, a national school health and wellbeing survey. Auckland, New Zealand: The University of Auckland.

Fordham, B. (2001). Caught in the cross-fire: Exploring the relationship between the impact on children of witnessing domestic violence and violent youth offending. Unpublished Masters thesis, Wellington, Victoria University of Wellington. 
Gilligan, R. (2006). Creating a warm place where children can blossom. Social Policy Journal of New Zealand, 28 , 36-45.

Goldblatt, H. (2003). Strategies of coping among adolescents experiencing interparental violence. Journal of Interpersonal Violence, 18, 532-552.

Hardesty, J. L., Campbell, J. C., McFarlane, J. M., \& Lewandowski, L A. (2008). How children and their caregivers adjust after intimate partner femicide. Journal of Family Issues, 29(1), 100-124.

Hassall, I., \& Fanslow, J. (2006). Family violence in New Zealand: We can do better. The New Zealand Medical Journal, $119,1830-1833$.

Henderson, S. (1996). Children who witness domestic violence. Social Work Now, 4, 31-36.

Herrenkohl, T., Sousa, C., Tajima, E., Herrenkohl, R., \& Moylan, C. (2008). Intersection of child abuse and children's exposure to domestic violence. Trauma, Violence, $\mathcal{E}$ Abuse, 9(2), 84-99.

Herrera, V., \& McCloskey, L. (2001). Gender differences in the risk for delinquency among youth exposed to family violence. Child Abuse \& Neglect, 25(8), 1037-1051.

Humphreys, J. (2001). Turnings and adaptations in resilient daughters of battered women. Journal of Nursing Scholarship, 3, 245-251.

Indermaur, D., Atkinson, L., \& Blagg, H. (1998). Working with adolescents to prevent domestic violence: Rural town model. Full report. Canberra, Australian Capital Territory: Crime Research Centre, University of Western Australia.

Jackson, S. (1998). Teenage dating violence. Unpublished doctoral thesis, Auckland University, Auckland, New Zealand.

Jaffe, P., Wilson, S., \& Wolfe, D. (1990). Children of battered women. Newbury Park, CA: Sage.

Joest, K. (2005). Multiple contexts of violence in the lives of adolescent females who have been exposed to domestic violence. Unpublished doctoral thesis, Virginia Polytechnic Institute and State University, Blacksburg, Virginia.

Kennedy, A. (2007). Homelessness, violence exposure, and school participation among urban adolescent mothers. Journal of Community Psychology, 35(5).

Kingi, P. (1999, July). The impact of violence on children: Vulnerability and resilience. Paper presented at the Children and Family Violence Effective Interventions Now Conference, Wellington, New Zealand. Retrieved October 28, 2008, from http: / / www.justice.govt.nz/pubs/ reports/1999/family_conference/author_11.html

Kitzmann, K., Gaylord, N., Holt, A., \& Kenny, E. (2003). Child witnesses to domestic violence: A meta-analytic review. Journal of Consulting and Clinical Psychology, 71, 339-352.

Laing, L. (2000). Children, young people and domestic violence. Australian Domestic E Family Violence Clearinghouse, 2, 1-28.

Landon, L. (2000, March 31). Shelters fear Child Act changes: Battered women will be less likely to seek help, they say: [Final Edition]. The Ottawa Citizen, p. A6. Retrieved August 24, 2008, from ProQuest Central database. (Document ID: 201086121).

Margolin, G., \& Gordis, E. (2000). The effects of family and community violence on children. Annual Review of Psychology, 51, 445-479.

Margolin, G., \& Vickerman, K. (2007). Posttraumatic stress in children and adolescents exposed to family violence: I. Overview and issues. Professional Psychology - Research and Practice, 38(6), 613-619.

Martin, J., Langley, J. D., \& Millichamp, J. (2006). Domestic violence as witnessed by New Zealand children. The New Zealand Medical Journal, 119(1228).

Mckenzie, M. (2003). New website hits home: Bursting the bubble: A guide for teenagers living with family violence. Domestic Violence and Incest Resource Centre Newsletter, 3, 8-12.

Millen, P. (1994). Children who witness spouse abuse: A review of the literature and reported strategies for intervention. Social Work Review, 6(4), 18-23.

Ministry of Social Development. (2002). Te Rito: New Zealand Family Violence Prevention Strategy. Wellington, New Zealand: Ministry of Social Development.

Mullender, A. (2004). Tackling domestic violence: Providing support for children who have witnessed domestic violence (Home Office Development and Practice Report No. 33). London: Home Office. Retrieved from http: / / www. homeoffice.gov.uk/rds/pdfs04/dpr33.pdf

Mullender, A., Hague, G., Imam, U., Kelly, L., Malos, E., \& Regan, L. (2002). Children's perspectives on domestic violence. London: Sage.

Mulroney, J. (2003). Australian prevention programmes for young people. Sydney, New South Wales: Australian Domestic and Family Violence Clearinghouse.

New Zealand Family Violence Clearinghouse. (2007). Current initiatives. Retrieved, 5 December, 2008, from http: / / www.nzfvc.org.nz/Initiatives.aspx

O'Keefe, M. (1996). The differential effects of family violence on adolescent adjustment. Child $\mathcal{E}$ Adolescent Social Work Journal, 13(1), 51-68.

Rhinas, J. (2006). Resiliency in the face of interparental violence: A qualitative investigation. Unpublished masters thesis, University of Saskatchewan, Saskatoon, Saskatchewan, Canada.

Seith, C., \& Bockman, I. (2008). Children and domestic violence: A study of their understandings, coping strategies and needs: Executive summary of Final Report to Swiss National Science Foundation, NFP 52. Zurich, Switzerland: Department of Education, University of Zurich.

Shepherd, P., \& Maxwell, G. (1999). Do children's programmes work? Occasional papers in criminology: New series. Wellington, New Zealand: Institute of Criminology, Victoria University of Wellington. 
Suzuki, S. (2005). The experiences of adults exposed to intimate partner violence as children: An exploratory qualitative study of resilience and protective factors. Unpublished doctoral thesis, Alient International University, San Diego, California.

van Heugten, K., \& Wilson, E. (2008). Building resilience in young people who have witnessed intimate partner violence. Te Awatea Review, 6(2), 9-13.

Vickerman, K., \& Margolin, G. (2007). Posttraumatic stress in children and adolescents exposed to family violence: II. Treatment. Professional Psychology: Research and Practice, 38(6), 620-628.

Wolfe, D. A., Gough, R., Reitzel-Jaffe, D., Grasley, C., Pittman, A-L., Lefebvre, L., et al. (1996). The youth relationships manual: A group approach with adolescents for the prevention of woman abuse and the promotion of healthy relationships. Thousand Oaks, CA: Sage.

Wood, B. (2006). Children and domestic violence in New Zealand. Wellington, New Zealand: UNICEF New Zealand.

World Health Organization. (1989). The reproductive health of adolescents: A strategy for action. A joint WHO/UNFPA/UNICEF statement. Geneva: WHO.

Youth Helpline. (2008). Youthline. Te Awatea Review, 6(1), 13. 